\title{
Renal shear wave elastography and urinary procollagen type III amino-terminal propeptide (uPIIINP) in feline chronic kidney disease
}

\author{
Chutimon Thanaboonnipat ${ }^{1,2}$, Saikaew Sutayatram ${ }^{1}$, Chollada Buranakarl ${ }^{1}$ and Nan Choisunirachon ${ }^{2^{*}}$ (D)
}

\begin{abstract}
Background: Chronic kidney disease (CKD) is one of the most common diseases occurring in cats. It is characterized by renal fibrosis, which is strongly correlated with impairment of renal function. Since renal biopsy is not performed routinely in clinical practice, the non-invasive method of ultrasonographic shear-wave elastography (SWE) was used to determine renal parenchymal stiffness. Currently, urinary procollagen type III amino-terminal propeptide (UPIIINP) is a renal fibrosis biomarker in humans. Moreover, PIIINP is increasingly applied for identification of fibrosis in various organs in animals.

Results: The Young's modulus (E) value on SWE, uPIIINP, and renal function were evaluated in 23 CKD cats and 25 healthy cats $(\mathrm{HC})$. The renal cortical E values were significantly higher than those of the renal medulla in both groups $(P<0.001)$. The $E$ values of the renal cortex and medulla were significantly higher in CKD cats than in $\mathrm{HC}(P<0.001$ and $P<0.01$, respectively). The E values, especially of the cortex, showed a significant positive correlation with concentrations of plasma creatinine $(P<0.001)$, blood urea nitrogen $(P<0.05)$, while they had a negative correlation with urine specific gravity $(P<0.001)$ and urine osmolality per plasma osmolality ratio $(P<0.01)$. The UPIIINP to creatinine ratios (uPIIINP/Cr) were significantly higher in CKD cats than in $\mathrm{HC}(P<0.01)$ and were highly correlated with renal cortical $E$ values $(P<0.001)$.
\end{abstract}

Conclusions: SWE might be an additively useful and non-invasive diagnostic imaging tool to evaluate renal parenchymal stiffness, which correlates with renal functional impairment in CKD cats. Moreover, the UPIIINP/Cr might be a promissing biomarker for adjunctive assessing the renal fibrosis in feline CKD.

Keywords: Cat, Chronic kidney disease (CKD), Urinary procollagen type III amino-terminal propeptide (uPIIINP), Renal fibrosis, Shear wave elastography (SWE)

\section{Background}

Chronic kidney disease (CKD) is a common disease in cats and has been increasingly diagnosed annually, particularly in aging cats [1-5]. Renal fibrosis is the hallmark of advanced CKD and strongly correlates with renal function impairment in humans and cats [6, 7]. Renal fibrosis causes an irreversible loss of normal tissue, diminished renal function, and end-stage renal disease (ESRD). Renal

\footnotetext{
* Correspondence: nan.c@chula.ac.th

${ }^{2}$ Department of Veterinary Surgery, Faculty of Veterinary Science,

Chulalongkorn University, 39 Henri-Dunant Road, Wangmai, Pathumwan,

Bangkok 10330, Thailand

Full list of author information is available at the end of the article
}

biopsy is the gold standard for diagnosing renal fibrosis [8]. However, it requires anesthesia and can cause several complications. The most common complication of renal biopsy is hemorrhage. Therefore, it is not performed routinely in clinical practice particularly in high-risk patients such as CKD cats [9].

Cats with CKD normally display non-specific signs $[10,11]$, and routine laboratory tests, such as blood creatinine concentration, are not sensitive enough for early CKD detection [12]. Abdominal ultrasonography can provide information on the renal parenchyma that is important for identifying the underlying causes of CKD.

(c) The Author(s). 2019 Open Access This article is distributed under the terms of the Creative Commons Attribution 4.0 International License (http://creativecommons.org/licenses/by/4.0/), which permits unrestricted use, distribution, and reproduction in any medium, provided you give appropriate credit to the original author(s) and the source, provide a link to the Creative Commons license, and indicate if changes were made. The Creative Commons Public Domain Dedication waiver (http://creativecommons.org/publicdomain/zero/1.0/) applies to the data made available in this article, unless otherwise stated. 
However, typical ultrasonographic findings, such as small and irregular kidneys or increased echogenicity of the cortex and/or medulla [13-16], are not specific for CKD, and are sometimes found in healthy cats [17].

Several methods are currently used in human medicine for the determination of renal fibrosis. One of the renal fibrosis biomarkers is urinary procollagen type III amino-terminal propeptide (uPIIINP) [8, 18]. Previous studies in people have reported that high urine PIIINP to creatinine ratio (uPIIINP/Cr) was highly associated with the severity of renal fibrosis and CKD progression $[8,19$, 20]. Moreover, in animals, PIIINP was also used as a fibrosis marker for assessing cardiac remodeling [21], idiopathic pulmonary fibrosis [22], and liver fibrosis in dogs [23].

In addition, renal ultrasonographic elastography (USE) is an imaging technique that has been increasingly applied in human medicine $[24,25]$. USE can evaluate tissue elasticity by differentiating between normal tissue and stiff tissue, which cannot be done using hyperechogenic images from B-mode ultrasonography [26]. USE examines the tissue hardness [27, 28], using tissue elasticity evaluation that is inversely proportional to stiffness [29]. As previously described, fibrous tissue infiltration in the renal parenchyma results in decreased elasticity [30]. The two main techniques of USE available are strain elastography (SE) and shear wave elastography (SWE) [26]. In human medicine, SWE has been widely performed to assess the renal parenchymal stiffness through the Young's modulus (E) in CKD patients $[25,31]$. Several studies have reported that human patients with CKD had renal E values significantly higher than those of healthy individuals [25, 31]. Therefore, renal USE shows promise as a diagnostic imaging method to detect the early stage of CKD [28, 32, 33].

In veterinary medicine, especially in cats, the use of UPIIINP has not been reported, and reports on the use of USE are limited and only include the use of SE on normal kidneys [34]. Therefore, the purposes of this study were, first, to compare the renal tissue stiffness observed through E values between healthy cats and CKD cats using SWE; second to evaluate the relationships between the renal tissue stiffness and functional renal parameters, including plasma creatinine concentration, blood urea nitrogen (BUN), urine specific gravity (USG), urine protein creatinine (UPC) ratio, urine osmolality to plasma osmolality (Uosm/Posm) ratio, and fractional excretion of sodium, potassium, chloride, and magnesium $\left(\mathrm{FE}_{\mathrm{Na}}, \mathrm{FE}_{\mathrm{K}}, \mathrm{FE}_{\mathrm{Cl}}\right.$, and $\mathrm{FE}_{\mathrm{Mg}}$ ) in both groups; and third to determine the relationship between uPIIINP/Cr levels and blood pressure, UPC ratio or renal E values.

\section{Methods}

\section{General materials}

This clinical, cross-sectional study was approved by the Chulalongkorn University Animal Care and Use
Committee (CU-ACUC), Faculty of Veterinary Science, Chulalongkorn University (Protocol number: 1731055). All client-owned cats, including healthy cats $(\mathrm{HC})$ and CKD cats that presented to the Small Animal Teaching Hospital, Faculty of Veterinary Science, Chulalongkorn University from September to December 2017, were considered for inclusion. The cats were considered to be $\mathrm{HC}$ if the history, physical examination, routine blood examinations, including complete blood count (CBC) and plasma biochemistry, USG, urinalysis, UPC ratio, abdominal radiographs, and abdominal ultrasound were normal. All cats tested negative for Feline Immunodeficiency Virus (FIV) and Feline Leukemia Virus (FeLV) infection using ELISA Test Kits (WITNESS ${ }^{\oplus}$ FeLV-FIV, Zoetis, New Jersey, USA). The CKD cats included in this study were defined based on a history of either structural or functional abnormalities of the kidneys for more than 3 months (stable CKD patients) and were categorized into IRIS stage 2, 3 and 4 CKD according to the International Renal Interest Society (IRIS) [35] staging system, in which the plasma creatinine concentrations equal to or higher than $1.6 \mathrm{mg} / \mathrm{dl}$. Additionally, all CKD cats underwent the same diagnostic procedures as the $\mathrm{HC}$ and had negative results for FIV and FeLV infection from ELISA Test Kits (WITNESS ${ }^{\bullet}$ FeLV-FIV, Zoetis, New Jersey, USA). Cats with ascites, infectious diseases, lymphoma, congenital kidney diseases, such as polycystic kidney disease, hydronephrosis, generalized peripheral edema, or nephroliths were excluded from this study.

A total of $3 \mathrm{ml}$ of blood was collected from each cat and placed in an EDTA tube for complete blood count $(\mathrm{CBC})$ and a heparinized tube for measurement of creatinine concentration, BUN, alanine aminotransferase (ALT), alkaline phosphatase (ALP), total protein, albumin, osmolality, and electrolytes $\left(\mathrm{Na}^{+}, \mathrm{K}^{-}, \mathrm{Cl}^{-}\right.$and $\mathrm{Mg}^{2}$ ${ }^{+}$). Urine was collected by voiding or catheterization for measuring the concentrations of creatinine, protein, electrolytes $\left(\mathrm{Na}^{+}, \mathrm{K}^{-}, \mathrm{Cl}^{-}\right.$and $\left.\mathrm{Mg}^{2+}\right)$, PIIINP, and osmolality. Indirect blood pressure in all cats was measured three times at the proximal hind leg or distal forelimb and the results were averaged. All ultrasonographic procedures were performed within a visit day.

\section{Analytical procedures}

Concentrations of creatinine, BUN, ALT, ALP, total protein, and albumin were determined within an hour of collection by automated analyzer (The IL ILab 650 Chemistry Analyzer, Diamond Diagnostic, MA, USA). Frozen plasma and frozen urine samples $\left(-20^{\circ} \mathrm{C}\right)$ were thawed to measure the osmolality and electrolytes concentration within a few weeks of collection. The plasma and urine osmolality were measured using automatic cryoscopic osmometer (OSMOMAT ${ }^{\bullet}$ 030, Gonotec $\mathrm{GmbH}$, Berlin, Germany), the plasma concentrations of 
electrolytes were analyzed using automated analyzer (ARCHITECT c16000 clinical chemistry analyzer, Abbott Laboratories, IL, USA) and the urine concentrations of electrolytes were analyzed using automated analyzer (COBAS INTEGRA 400 plus, Roche Diagnostics, Rotkreuz, Switzerland). USG was determined within an hour of collection using a refractometer (Master Refractometer; ATAGO ${ }^{\circ}$, Tokyo, Japan). Measurement of blood pressure was performed using a Doppler blood pressure instrument (Vet-Dop 2 ${ }^{\mathrm{m}}$, Vmed Technology, WA, USA). The microscopic observation of the urine sediment was performed prior to the measurement of the UPC to exclude the urinary tract infection. The UPC ratio was performed by measuring urine protein concentrations after precipitation with 3\% sulphosalicylic acid [36]. Fractional excretions $\left(\mathrm{FE}_{\mathrm{Na}}, \mathrm{FE}_{\mathrm{K}}, \mathrm{FE}_{\mathrm{Cl}}\right.$, and $\left.\mathrm{FE}_{\mathrm{Mg}}\right)$ were calculated using the formula as previously described [36]. Urinary PIIINP concentrations were determined in frozen urine samples $\left(-80^{\circ} \mathrm{C}\right)$ within 2 months of collection using a sandwich enzyme-linked immunosorbent assay (ELISA) kit (Cat Procollagen Type III N-Terminal Propeptide (PIIINP) ELISA Kit, Cat. No. MBS060292, MyBioSource ${ }^{\circ}$, CA, USA), following the manufacturer's instructions. Urine samples were assayed in duplicate, with an intra-assay and inter-assay coefficient of variation less than $15 \%$. The uPIIINP/Cr levels were calculated and expressed as $\mathrm{ng} / \mathrm{mgCr}$.

\section{SWE procedure}

The ultrasonographic examinations were performed without sedation. The cats were manually restrained and positioned in right and left lateral recumbency for each ipsilateral site of kidneys. Routine preparation for ultrasonographic examination, including hair clipping and acoustic gel coupling, was performed. All cats were screened with B-mode abdominal ultrasound, and the sagittal, dorsal, and transverse planes of the kidneys were recorded using a $9 \mathrm{MHz}$-bandwidth of a linear transducer (Resona-7, Mindray Medical International, Shenzhen, China). SWE was then performed on the sagittal plane of each kidney. The elastograms were displayed using a dual-screen, consisting of a B-mode image and an SWE color quantitative elastogram overlaid on B-mode. The fixed region of interest (ROI) was adjusted as wide as possible to cover both the renal cortex and renal medulla while attempting to control the high reliability (RLB) map during the procedure. The RLB map indicates the quality of shear wave image in a number percentage. The elasticity results measured from shear wave images with higher RLB percentages are more reliable. The elastogram color scale expressed a red color to represent the hardest tissues, whereas a blue color represented the softest tissues.
The $\mathrm{E}$ value in kilopascal $(\mathrm{kPa})$ unit was selected for representation of the tissue stiffness [37]. A stiff material has a higher E value than a soft material $[37,38]$. Three separate elastograms were selected, and $\mathrm{E}$ values were measured at the superficial, mid renal parenchymal region using a circular electrical caliper which circular size varied according to the thickness of the renal cortical and medullary parenchyma in both HC and CKD cats (Fig. 1), and the measurements from each elastogram were averaged.

\section{Statistical analysis}

Statistical analyses were performed by GraphPad Prism 7 software (GraphPad Software; CA; USA). Results were expressed as mean \pm standard deviation (SD). Normality distributions were tested with the Shapiro-Wilk test. The average $\mathrm{E}$ value results between left and right kidneys in each group were analyzed by paired $t$-test. The average $\mathrm{E}$ values and $\mathrm{uPIIINP} / \mathrm{Cr}$ levels were compared between groups by the unpaired t-test or Mann Whitney test. Pearson's correlation coefficient and Spearman's correlation coefficient were used to investigate the correlations between parameters. Statistical significance was considered if the $P$-value was less than 0.05 .

\section{Results}

A total of $25 \mathrm{HC}$ and $23 \mathrm{CKD}$ cats were included in this study. The mean ages of the $\mathrm{HC}$ and CKD cats were 4.5 \pm 3.4 years (median 3 years; range 8 months -10 years) and $9.7 \pm 5.1$ years (median 9years; range 3-21 years), respectively. There were 11 females (4 intact and 7 neutered) and 14 males (6 intact and 8 neutered) in the $\mathrm{HC}$ group, and there were 15 females (10 intact and 5 neutered) and 8 males (2 intact and 6 neutered) in the CKD group. The mean bodyweight of $\mathrm{HC}$ was $4.1 \pm 0.9 \mathrm{~kg}$ (range 2.9-5.9 kg), while the mean body weight of CKD cats was $3.7 \pm 0.9 \mathrm{~kg}$ (range; 2.6-5.9). The body condition scores (BCS) of both groups were comparable and ranged from a score of 2-4 out of 5 in each group, with a mean of $3.2 \pm 0.6$ and $3.0 \pm 0.4$ for $\mathrm{HC}$ and CKD cats, respectively. The $\mathrm{HC}$ consisted of Domestic shorthair (18), Persian (5), and American shorthair (2), and the CKD cats were Domestic shorthair (22) and Persian (1). The CKD cats were belonging to IRIS stage $2(82.6 \%)$, stage $3(13.1 \%)$ and stage 4 (4.3\%).

Ultrasonographically, the kidneys in $\mathrm{HC}$ had normal shape, contour, echogenicity, and echotexture, with a mean length of $3.6 \pm 0.4$ and $3.5 \pm 0.4 \mathrm{~cm}$ for the right and left kidneys, respectively. In contrast, CKD cats had irregular renal outlines, increased echogenicity of the cortex and/or medulla, and decreased corticomedullary demarcation. The CKD cats also had significantly shorter renal length (mean length of $3.1 \pm 0.5$ and $3.1 \pm 0.6 \mathrm{~cm}$ for the right and left kidneys, 


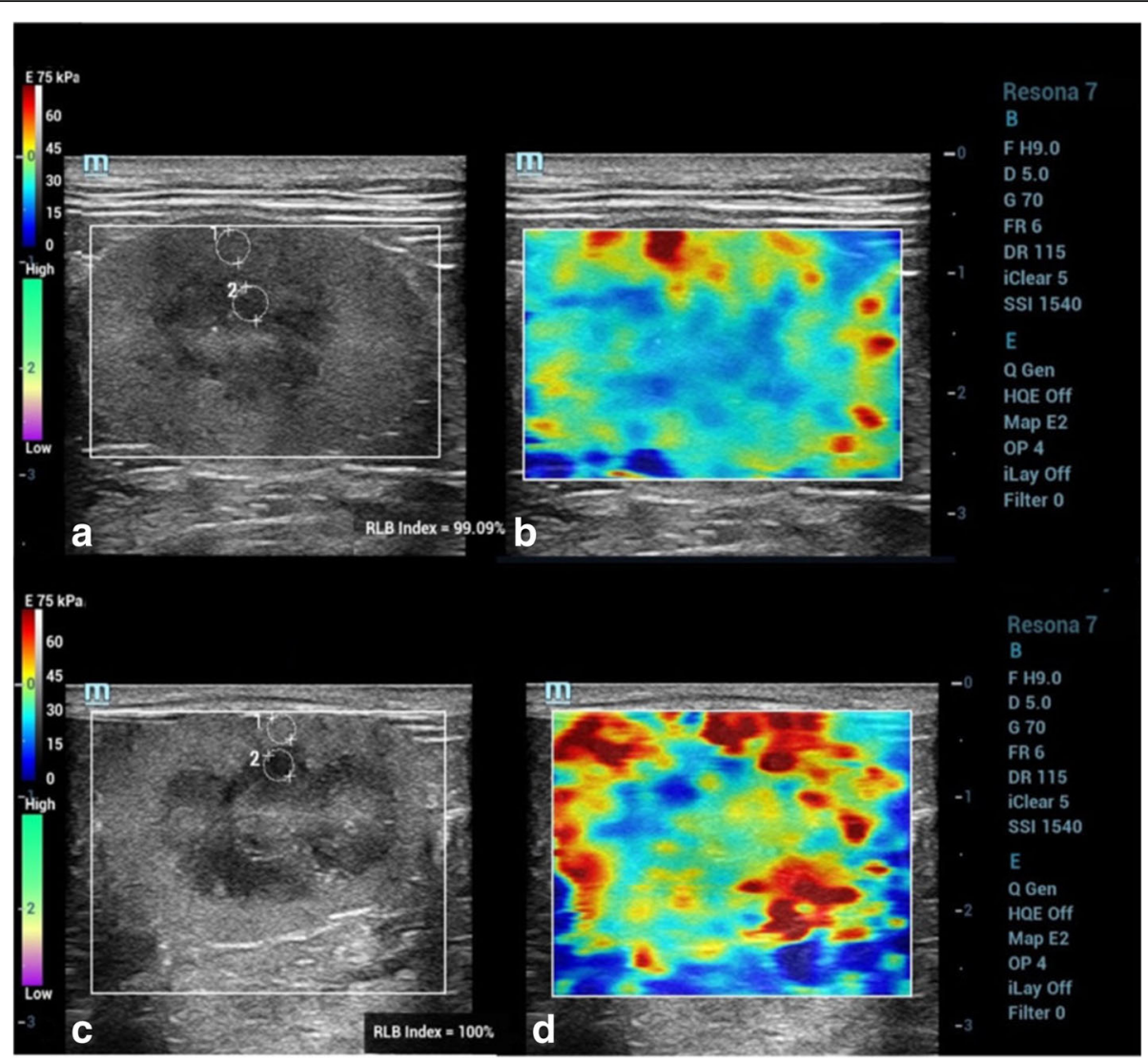

Fig. 1 B-mode ultrasound images; $\mathbf{a}$, c and color quantitative elastogram overlaid on the ROI on the B-mode; $\mathbf{b}$, $\mathbf{d}$ between a healthy cat (HC); $\mathbf{a}$, b comparing to a chronic kidney disease (CKD) cat; $\mathbf{c}$, $\mathbf{d}$. Regions of interest (ROIs) were drawn over the mid renal cortex and medulla to measure the Young's modulus (E) value

respectively) than the $\mathrm{HC}$ (Right kidney; $P<0.01$ and Left kidney; $P<0.001$ ).

The average blood pressure of HC group was significantly lower than that of CKD cats $(129.2 \pm 17.3 \mathrm{mmHg}$ and $150.9 \pm 26.4 \mathrm{mmHg}$, respectively; $P<0.01$ ). Urine collection was achieved in 39 cats, which were $19 \mathrm{HC}$, and $20 \mathrm{CKD}$ cats. The functional renal parameters of both groups, including plasma creatinine concentration, BUN, USG, UPC ratio, Uosm/Posm ratio, $\mathrm{FE}_{\mathrm{Na}}, \mathrm{FE}_{\mathrm{K}}$, $\mathrm{FE}_{\mathrm{Cl}}$, and $\mathrm{FE}_{\mathrm{Mg}}$, are summarized in Table 1. Plasma creatinine, BUN concentration and UPC ratio of CKD cats were significantly higher than those of $\mathrm{HC}(P<0.001)$, while USG and Uosm/Posm ratio of CKD cats were significantly lower than those of $\mathrm{HC}(P<0.001)$. All FE of electrolytes, except $\mathrm{FE}_{\mathrm{Na}}$, were significantly higher in CKD cats than in HC $(P<0.001)$.

The renal elasticity on the SWE of the $25 \mathrm{HC}$ and 23 CKD cats were reported as average $\mathrm{E}$ values calculated from the right and left kidneys. The average $E$ values of the renal cortex and medulla were not significantly different between the right and left kidneys in each group (Table 2). Age, bodyweight, and BCS did not affect the average $\mathrm{E}$ values of the cortex or medulla in $\mathrm{HC}$.
Regarding gender, the average renal $\mathrm{E}$ values of male cats and female cats were not significantly different. However, average renal cortical $\mathrm{E}$ values were significantly higher than those of the renal medulla in both groups $(P<0.001)$. Moreover, the average $\mathrm{E}$ values of the renal cortex and medulla of CKD cats were significantly higher than those of $\mathrm{HC}(P<0.001$ and $P<0.01$, respectively) (Fig. 2).

The correlations between average renal $\mathrm{E}$ values and plasma creatinine concentrations or BUN in the 48 cats from both groups, and the correlations between the average renal E value and USG, UPC ratio, Uosm/Posm ratio, $\mathrm{FE}_{\mathrm{Na}}, \mathrm{FE}_{\mathrm{K}}, \mathrm{FE}_{\mathrm{Cl}}$, or $\mathrm{FE}_{\mathrm{Mg}}$ in 39 cats, from both the $\mathrm{HC}$ and CKD groups, were evaluated (Table 3). The E values of the cortex showed a significant positive correlation with concentrations of plasma creatinine $(P<0.001)$, BUN $(P<0.05)$, and $\mathrm{FE}_{\mathrm{Cl}}(P<0.01)$, while it showed a negative correlation with USG $(P<0.001)$ and Uosm/ Posm $(P<0.01)$ (Fig. 3).

The average uPIIINP/Cr values of $17 \mathrm{HC}$ and $20 \mathrm{CKD}$ cats were compared, and the results showed that CKD cats had average uPIIINP/Cr values significantly higher than those of $\mathrm{HC}$ (mean uPIIINP/Cr of $34.9 \pm 29.4$ and 
Table 1 Functional renal parameters include concentrations of plasma creatinine and BUN, USG, UPC ratio, Uosm/Posm ratio and $\mathrm{FE}_{\mathrm{Na}}, \mathrm{FE}_{\mathrm{K}}, \mathrm{FE}_{\mathrm{Cl}}$, $\mathrm{FE}_{\mathrm{Mg}}$ of the healthy cats $(\mathrm{HC})$ and chronic kidney disease (CKD) cats

\begin{tabular}{|c|c|c|c|c|}
\hline Parameters & No. of s samples & Healthy cats & CKD cats & Reference intervals \\
\hline Plasma creatinine $(\mathrm{mg} / \mathrm{dL})$ & 48 & $1.36 \pm 0.19$ & $2.59 \pm 0.99^{* * *}$ & $0.6-1.6$ \\
\hline $\mathrm{B} \cup \mathrm{N}(\mathrm{mg} / \mathrm{dL})$ & 48 & $22.39 \pm 4.62$ & $39.74 \pm 22.79^{* * *}$ & $14-36$ \\
\hline USG & 39 & $1.055 \pm 0.01$ & $1.034 \pm 0.015^{* * *}$ & $1.035-1.060$ \\
\hline UPC ratio & 9 & $0.09 \pm 0.1$ & $0.96 \pm 1.71^{* * *}$ & $<0.2^{\mathrm{a}}$ \\
\hline Uosm/Posm ratio & 39 & $5.95 \pm 1.56$ & $2.95 \pm 2.12^{* * *}$ & NA \\
\hline $\mathrm{FE}_{\mathrm{Na}}(\%)$ & 39 & $0.58 \pm 0.29$ & $2.57 \pm 3.02$ & $<1$ \\
\hline $\mathrm{FE}_{\mathrm{K}}(\%)$ & 39 & $18.39 \pm 6.41$ & $44.69 \pm 27.41^{* * *}$ & $<20$ \\
\hline $\mathrm{FE}_{\mathrm{Cl}}(\%)$ & 39 & $1.08 \pm 0.47$ & $4.79 \pm 4.56^{* * *}$ & $<1$ \\
\hline $\mathrm{FE}_{\mathrm{Mg}}(\%)$ & 39 & $2.41 \pm 1.57$ & $9.11 \pm 7.86^{* * *}$ & $<5.4$ \\
\hline
\end{tabular}

${ }^{a}$ Reference of UPC ratio in cats $=$ non-proteinuric $(<0.2)$, borderline $(0.2-0.4)$, proteinuric $(>0.4)$

$B U N$ blood urea nitrogen, USG urine specific gravity, UPC ratio urine protein creatinine ratio, Uosm/Posm ratio urine osmolality per plasma osmolality ratio, $F E_{N a}$ fractional excretion of sodium, $F E_{K}$ fractional excretion of potassium, $F E_{C l}$ fractional excretion of chloride, $F E_{M g}$ fractional excretion of magnesium

NA denotes no available data

Data are presented as mean \pm SD

${ }^{* * *}$ Statistically difference between groups was made using Unpaired t- test, $P<0.001$

$8.1 \pm 5.2 \mathrm{ng} / \mathrm{mgCr}$ for $\mathrm{CKD}$ cats and $\mathrm{HC}$, respectively; $P$ $<0.01$ ) (Fig. 4). No significant correlations were presented between uPIIINP/Cr and blood pressure or UPC ratio. A significant positive correlation $(P<0.001)$ was found between uPIIINP/Cr levels and average renal cortical E values (Fig. 5), while uPIIINP/Cr levels were not significantly correlated with average renal medullary $\mathrm{E}$ values.

\section{Discussion}

USE can differentiate normal tissue from pathological tissue with an altered elasticity and increased stiffness, such as a fibrotic process $[25,39]$. In veterinary medicine, the use of elastography has been described in a small number of studies on normal kidneys of various dog breeds [29] including beagles [40] and various cat breeds [34]. It has also been used to study canine mammary tumors [41, 42], and canine malignant lymph nodes [43]; however, it has not been used in renal disease.

Table 2 The Young's modulus (E) values ( $\mathrm{kPa}$ ) of renal parenchyma between healthy cats group and CKD cats group

\begin{tabular}{|c|c|c|c|c|}
\hline \multirow[t]{2}{*}{ Group } & \multicolumn{2}{|l|}{ E value of LK } & \multicolumn{2}{|l|}{ E value of RK } \\
\hline & Cortex & Medulla & Cortex & Medulla \\
\hline \multirow[t]{2}{*}{$\overline{\mathrm{HC}}$} & $38.40 \pm 7.12$ & $30.16 \pm 5.97$ & $40.34 \pm 10.42$ & $32.73 \pm 7.04$ \\
\hline & $(22.91-55.58)$ & $(19.43-40.13)$ & $(23.70-53.74)$ & (18.27-49.30) \\
\hline \multirow[t]{2}{*}{ CKD } & $51.89 \pm 11.25$ & $39.16 \pm 13.07$ & $51.97 \pm 12.65$ & $36.60 \pm 10.06$ \\
\hline & $(22.55-74.42)$ & (20.19-82.13) & $(23.38-75.60)$ & $(15.38-66.51)$ \\
\hline
\end{tabular}

$E$ value the Young's modulus values in kilopascal unit, $L K$ left kidney, $R K$ right kidney, $H C$ healthy cats group, CKD chronic kidney disease cats group Data are expressed as mean $\pm S D$ and range

The average $E$ values between left and right kidneys in each group were analyzed by Paired t-test
SWE was performed in this study because it is the newest USE technique [44]; it also provides better information on elasticity than SE, in which the result is highly dependent upon operator experience [45]. Other imaging techniques have also been used to facilitate an early CKD diagnosis in cats, such as: contrast-enhanced ultrasound examination in domestic and purebred cats [46], and renal resistive index (RRI) in domestic cats [47]. However, methods such as RRI are difficult to evaluate, especially in CKD cats with renal vascular impairment and decreased renal blood flow [47]. Peng and colleagues [25] reported that human patients with CKD had stiffer kidneys than healthy people, when using SWE. Therefore, SWE may be more useful for the investigation of renal parenchymal stiffness than conventional B-mode ultrasound, especially in CKD cats.

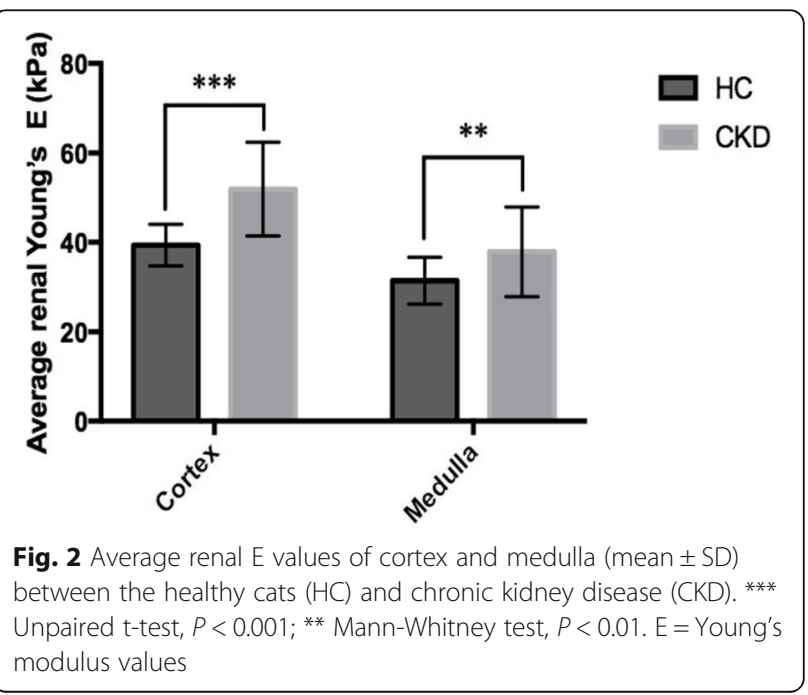


Table 3 Correlations between the average renal Young's modulus (E) values and plasma creatinine concentration, BUN, USG, UPC ratio, Uosm/Posm ratio and $\mathrm{FE}_{\mathrm{Na}}, \mathrm{FE}_{\mathrm{K}}, \mathrm{FE}_{\mathrm{Cl}}$, $\mathrm{FE}_{\mathrm{Mg}}$ in the healthy cats $(\mathrm{HC})$ and chronic kidney disease (CKD) cats

\begin{tabular}{llll}
\hline Parameters & $\begin{array}{l}\text { No. of } \\
\text { samples }\end{array}$ & $\begin{array}{l}\text { Average E values } \\
\text { of cortex } \\
r\end{array}$ & $\begin{array}{l}\text { Average E values } \\
\text { of medulla } \\
r\end{array}$ \\
\hline Plasma creatinine & 48 & $0.509^{* * *}$ & $0.329^{*}$ \\
BUN & 48 & $0.361^{*}$ & 0.188 \\
USG & 39 & $-0.567^{* * *}$ & -0.255 \\
UPC ratio & 39 & 0.233 & -0.045 \\
Uosm/Posm ratio & 39 & $-0.582^{* * *}$ & -0.306 \\
$\mathrm{FE}_{\mathrm{Na}}$ & 39 & 0.256 & 0.089 \\
$\mathrm{FE}_{\mathrm{K}}$ & 39 & 0.250 & -0.219 \\
$\mathrm{FE}_{\mathrm{Cl}}$ & 39 & $0.506^{* *}$ & $0.478^{* *}$ \\
$\mathrm{FE}_{\mathrm{Mg}}$ & 39 & 0.293 & 0.079 \\
\hline Evale the Youngs & &
\end{tabular}

$E$ value the Young's modulus values, BUN blood urea nitrogen, USG urine specific gravity, UPC ratio urine protein creatinine ratio, Uosm/Posm ratio urine osmolality plasma osmolality ratio, $F E_{N a}$ fractional excretion of sodium, $F E_{K}$ fractional excretion of potassium, $F E_{C I}$ fractional excretion of chloride, $F E_{M g}$ fractional excretion of magnesium

Correlations between parameters were made using Spearman correlation, ${ }^{*} P<$ $0.05 ;{ }^{* *} P<0.01{ }^{* * *} P<0.001$
As previously described, the renal length in cats may vary with gonadal status [48]. However, in this study, both groups contained similar numbers of intact and neutered cats. Thus, the shorter average renal length in CKD cats compared with that in $\mathrm{HC}$ cats was mainly due to disease progression, as decreased renal size is a common finding in advanced CKD [15].

In contrast with the results from previous studies in canine, the $E$ values did not vary between the left and right kidneys in either group of cats. This might be because the location of the feline kidney, particularly in right kidney, interferes less with the SWE procedure compared with the location of right kidney in dogs, which is more cranial and nearer to the rib cage $[40,49]$. Therefore, respiratory motion was observed to be more problematic when performing the SWE of the right kidney in comparison to the left kidney in dogs [29].

In agreement with the findings of previous studies in dogs and humans $[29,50]$, our results show that age, gender, bodyweight, and BCS did not affect the renal E values in $\mathrm{HC}$ cats. However, in this study, the small number of animals is an important limitation in evaluating the influence of demographic variables on elastography. In addition, the ages between groups were unmatched. The $\mathrm{HC}$ group was younger than the CKD group, because
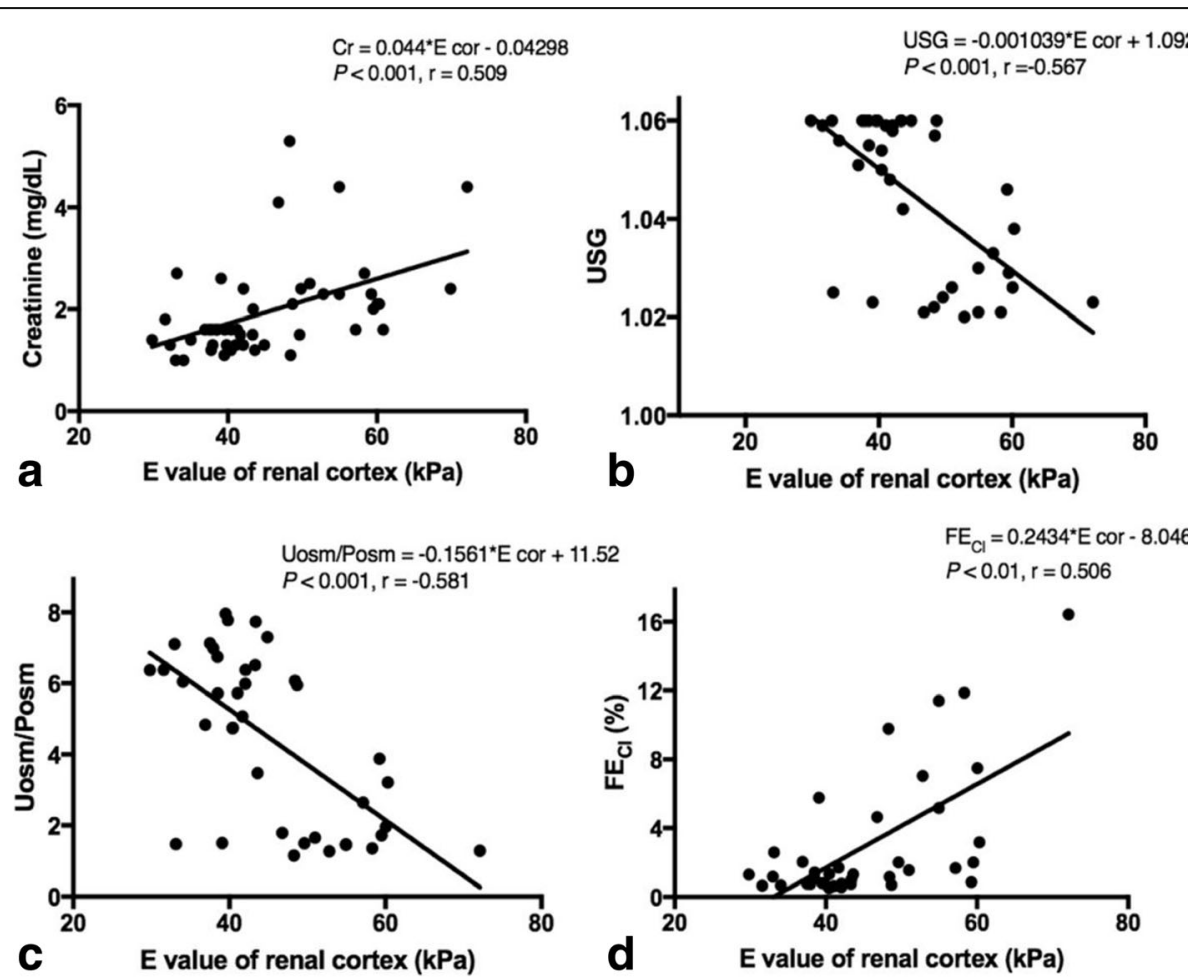

Fig. 3 Correlations between renal cortical E values and other renal parameters using Spearman correlation; a average renal cortical E values and plasma creatinine; $\mathbf{b}$ average renal cortical E values and USG; $\mathbf{c}$ average renal cortical E values and Uosm/Posm; $\mathbf{d}$ average renal cortical E values and $\mathrm{FE}_{\mathrm{Cl}} \mathrm{E}=$ Young's modulus values; USG = Urine specific gravity; Uosm/Posm = Urine osmolality per plasma osmolality; $\mathrm{FE}_{\mathrm{Cl}}=\mathrm{Fractional}$ excretion of chloride 


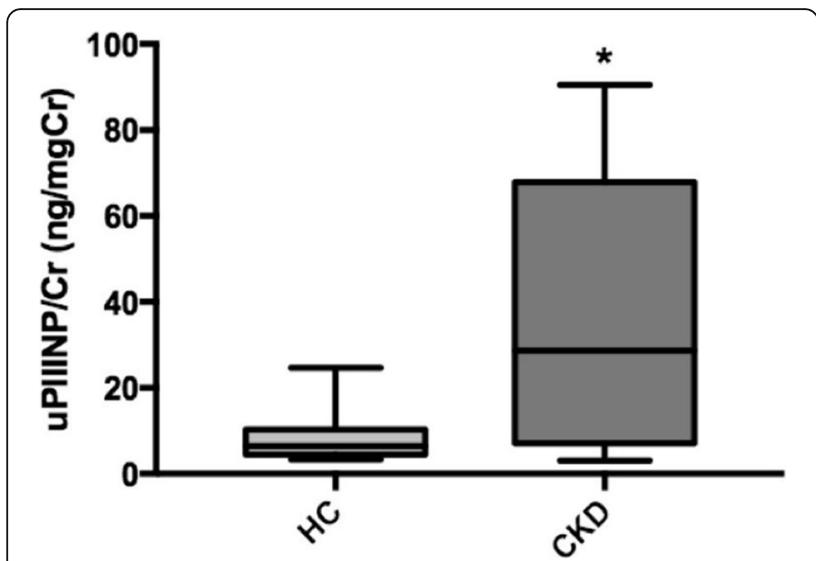

Fig. 4 Box and whisker plot illustrating uPIIINP/Cr between the healthy cats (HC) and chronic kidney disease (CKD). * Statistically difference between groups was made using Mann-Whitney test, $P<0.01$. uPIIINP/ $\mathrm{Cr}=$ Urine Procollagen Type III N-Terminal Propeptide to creatinine ratio

CKD has high incidence in senior cats. Therefore, the ability to obtain a $\mathrm{HC}$ group with a comparable age to that of the CKD group is challenging.

The elasticity of the renal cortex was significantly less than that of the renal medulla in both groups, which corresponds to SWE studies conducted in humans $[25,27]$ and pigs [45]. In contrast, the opposite results were reported in SE studies of healthy dogs [40] and healthy cats [34]. This disagreement among studies might result from the differences in ultrasound modalities and picture acquisition techniques. Further studies that compare between techniques would provide more clinical information of renal elasticity. From our findings, the lower elasticity of the renal cortex compared with the renal medulla could be explained by the difference in the normal physiological

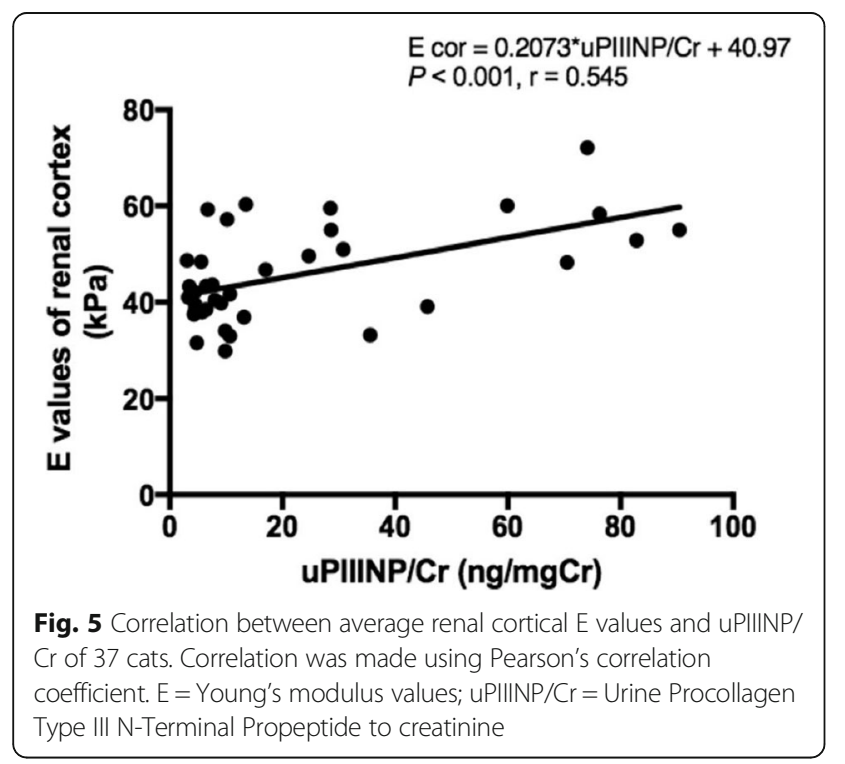

blood supply to the kidneys. Tissue elasticity is highly influenced by the degree of vascular pressure, and a greater proportion of the cardiac blood flow is distributed to the renal cortex than to the renal medulla [27].

Both the renal cortical and medullary E values of CKD cats were significantly higher than those of $\mathrm{HC}$ cats, which demonstrated that CKD cats had increased kidney stiffness. These results correspond with the studies by Guo et al. [28], Hu et al. [32], Samir et al. [33], and Peng et al. [25] in humans with CKD. However, the results of this study showed that there was an overlap between the average renal $\mathrm{E}$ values of $\mathrm{HC}$ cats and CKD cats. This might limit the use of USE for the definitive diagnosis of CKD. Rather, USE should be used as an adjunctive tool for more accurate detection and more informative monitoring of feline CKD. Furthermore, USE might assist in the diagnosis and treatment planning of renal disease in subclinical cases.

It is commonly known that renal tubulointerstitial fibrosis is the final common pathway of kidney disease [51], and is highly correlated with impairment of renal function in both humans [52, 53] and cats [54, 55]. Renal tubular functions including the absorption and excretion of water and electrolytes, were evaluated by measuring the Uosm/Posm ratio, $\mathrm{FE}_{\mathrm{Na}}, \mathrm{FE}_{\mathrm{K}}, \mathrm{FE}_{\mathrm{Cl}}$, and $\mathrm{FE}_{\mathrm{Mg}}$ in this study.

The results revealed that renal cortical $\mathrm{E}$ values had significant positive correlations with plasma creatinine concentrations, $\mathrm{BUN}$, and $\mathrm{FE}_{\mathrm{Cl}}$, while significant negative correlations existed with USG and Uosm/Posm ratio. These results correspond with the study by Lin et al. [24] in humans, in which renal elasticity was associated with a deterioration of renal function in patients with CKD. In this study, CKD cats exhibited a urinary concentrating defect leading to lower urine osmolality and Uosm/Posm ratio than in $\mathrm{HC}$ cats. Moreover, fractional excretion of electrolytes $\left(\mathrm{FE}_{\mathrm{e}}\right)$ has been reported to be a highly sensitive parameter for the evaluation of tubular impairment in dogs with advanced CKD [36]. Additionally, it has been demonstrated that $\mathrm{FE}_{\mathrm{Mg}}$ may be a useful marker of the severity of tubular cell damage, as it has been positively correlated with the stage of tubulointerstitial fibrosis in humans [56].

Additionally, our findings indicate that the renal cortical $E$ value was predominantly correlated with renal functions compared with that of the renal medullary $\mathrm{E}$ value. The reason for this could be that the renal cortex contains the glomeruli, which are responsible for plasma filtration [57], as well as the proximal tubules, which are responsible for the reabsorption and secretion of substances, particularly of electrolytes [58].

However, the urine osmolality and $\mathrm{FE}_{\mathrm{e}}$ vary depending on several exogenous and endogenous factors especially diet and hydration status [59]. In this study, we attempted 
to avoid the influence of hydration status through complete history taking and physical examination, and only included normally hydrated cats in our study. However, the effect of food on these parameters could not be controlled in this study, as the use of a prescription diet is a clinical recommendation in the management of CKD. Therefore, this might be an additional limitation of our study.

The uPIIINP/Cr ratio, which was strongly correlated with the progression of interstitial fibrosis in kidney biopsies from human patients $[8,18,19]$, was significantly higher in CKD cats than in $\mathrm{HC}$ cats. This corresponds to the results of human studies $[8,18,19]$, and the results of canine studies that used PIIINP as a marker of fibrosis in cardiac remodeling [21], idiopathic pulmonary fibrosis [22], and liver fibrosis [23]. Moreover, no significant correlation was found between the uPIIINP/Cr and blood pressure or UPC ratio. This also corresponds to the results of human research, in which uPIIINP was not dependent on the degree of proteinuria [19].

Urinary transforming growth factor beta 1 (TGF- $\beta 1$ ) is considered the most popular mediator for detecting the severity of renal fibrosis in cats [60]. However, the current gold standard method for identifying fibrosis is still a kidney biopsy $[8,61]$. Although, it has been reported that urinary TGF- $\beta 1$ concentration is increased in CKD cats $[62,63]$ and is correlated with histopathological evidence of interstitial fibrosis in cats [60], it has also been reported that urinary TGF- $\beta 1$ shows no significant association with worsening renal function in both humans [61] and cats [60]. While, uPIIINP has been evaluated in human patients at various stages of CKD, the uPIIINP/Cr has been correlated with the degree of renal function impairment, as well as with the severity of renal fibrosis $[8,18-20]$. In addition, uPIIINP levels correlated with urinary TGF- $\beta 1$ in human studies [19]. Therefore, uPIIINP has been considered as one of the reliable markers of renal fibrosis in humans $[8,19]$. Furthermore, as PIIINP has a low molecular weight (42 $\mathrm{kDa}$ ), it is filtered by the glomeruli and reabsorbed in the proximal tubules $[8,18,19]$. Thus, an elevation in uPIIIINP could indicate reduced tubular reabsorption capacity due to the progression of renal fibrosis. Moreover, it has previously been shown in human studies [19] and in our study that the level of uPIIINP is not related to the degree of proteinuria. It might be of use as an adjunct biomarker for the detection of renal fibrosis in cats; however, the value of UPIIINP at each stage of renal fibrosis and the concomitant histopathology in cats is currently still unknown.

In this study, a statistically positive and moderate correlation was found between the uPIIINP/Cr level and the average renal cortical $\mathrm{E}$ values, suggesting that the renal cortical $\mathrm{E}$ value might be one of the indicators to assist in the evaluation of renal fibrosis in CKD cats.
In veterinary medicine, information concerning renal function parameters and renal elasticity in cats has not been reported. Moreover, the relationship between the uPIIINP/Cr level and renal elasticity in CKD cats has not been determined. This is the first report relating the renal elasticity, as determined with SWE, to the uPIIINP/Cr in CKD cats. This information would be useful for clinical practitioners and would be of interest to researchers in further study.

The major limitation of this study is that we did not perform a renal histopathological examination for comparison with the renal elasticity determined by USE and the uPIIINP/Cr results, due to the invasive nature of the biopsy. Therefore, further studies should be considered. The second limitation is that the number of healthy cats included in the study was not sufficient to evaluate the influence of demographic variables on SWE. Additionally, the $\mathrm{HC}$ group and CKD group were not age-matched. Further study into the effect of age and BCS on the renal elasticity would provide more reliable information. The third limitation is that other uncontrollable factors of client-owned cats, such as different types of commercial foods, might influence the Uosm/Posm ratio and $\mathrm{FE}_{\mathrm{e}}$ results in this study. A further limitation is that we could not collect urine samples from all cats.

\section{Conclusions}

USE can be used an additive diagnostic imaging method for the evaluation and monitoring of feline CKD. Plasma creatinine, $\mathrm{BUN}$, and $\mathrm{FE}_{\mathrm{Cl}}$ had a positive correlation with renal elasticity, while USG and Uosm/Posm ratio revealed a negative correlation with renal elasticity. The renal cortex in both groups had lower elasticity than the renal medulla, and the kidneys of CKD cats were stiffer than those of $\mathrm{HC}$ in this study. Moreover, the renal cortical $\mathrm{E}$ values were significantly correlated to the uPIIINP/Cr levels. The results suggest that renal SWE might be an easy-to-use diagnostic tool, which may be applied as adjunct for the detection and monitor of feline CKD. Furthermore, the uPIIINP/Cr levels are higher in CKD cats. Therefore, the uPIIINP/Cr might also be a promising biomarker for adjunctive assessing the renal fibrosis in CKD cats. However, further studies are needed to elucidate the clinical value of USE in terms of evaluation and monitoring of feline CKD and to construct a correlation between uPIIINP/Cr and degree of renal fibrosis from histopathology in cats.

\section{Abbreviations}

BCS: Body condition score; BUN: Blood urea nitrogen; CBC: Complete blood count; CKD: Chronic kidney disease; CU-ACUC: Chulalongkorn University Animal Care and Use Committee; E: The Young's modulus (E) value Standard deviation; ECM: Extracellular matrix; ESRD: End-stage renal disease; $\mathrm{FE}_{\mathrm{e}}$ : Fractional excretion of electrolyte; $\mathrm{FE}_{\mathrm{Na}}, \mathrm{FE}_{\mathrm{K}}, \mathrm{FE}_{\mathrm{Cl}}$, and $\mathrm{FE}_{\mathrm{Mg}}$ : Fractional excretion of sodium, potassium, chloride, and magnesium; HC: Healthy cats; kPa: kilopascal; mmHg: Millimeter of mercury; RLB: Reliability; ROl: Region of interest; SD: Standard deviation; SE: Strain elastography; SWE: Shear-wave 
elastography; TGF- $\beta 1$ : Transforming growth factor beta 1; Uosm/Posm: Urine osmolality to plasma osmolality ratio; UPC: Urine protein creatinine; UPIIINP: Urinary procollagen type III amino-terminal propeptide; UPIIINP/ Cr: Urine PIIINP to creatinine ratio; USE: Ultrasonographic elastography; USG: Urine specific gravity

\section{Acknowledgments}

We would like to thank you the all technical recommendations from Mindray Medical (Thailand).

\section{Funding}

This study was granted from the 100th Anniversary Chulalongkorn University for Doctoral Scholarship and the 90th Anniversary of Chulalongkorn University Fund (Ratchadaphiseksomphot Endowment Fund). The funders supported the data collection, laboratory equipment and analysis and publication fee.

\section{Availability of data and materials}

The datasets used and/or analysed during the current study are available from the corresponding author on reasonable request.

\section{Authors' contributions}

Study conception and design: $C T, S S, C B$ and NC; Acquisition of data: $C T$ and $N C$; Laboratory test: $C T$ and $C B$; Analysis and interpretation of data: $C T, S S, C B$ and NC; Drafting of manuscript: CT, SS and NC; Critical revision: $C T, S S, C B$ and NC; All authors read and approved the final manuscript.

\section{Ethics approval}

All procedures followed were in accordance with the ethical standards of the Chulalongkorn University Animal Care and Use Committee (CU-ACUC), Faculty of Veterinary Science, Chulalongkorn University (Protocol number: 1731055). The owners gave consent for their pets to be part of this study.

\section{Consent for publication}

Written informed consent was obtained from the cats' owners for publication of this manuscript.

\section{Competing interests}

The authors declare that they have no competing interests.

\section{Publisher's Note}

Springer Nature remains neutral with regard to jurisdictional claims in published maps and institutional affiliations.

\section{Author details}

'Department of Veterinary Physiology, Faculty of Veterinary Science, Chulalongkorn University, Bangkok, Thailand. ${ }^{2}$ Department of Veterinary Surgery, Faculty of Veterinary Science, Chulalongkorn University, 39 Henri-Dunant Road, Wangmai, Pathumwan, Bangkok 10330, Thailand.

Received: 24 July 2018 Accepted: 29 January 2019

Published online: 11 February 2019

\section{References}

1. Lulich JP, Osborne CA, O'Brien TD, Polzin DJ. Feline renal failure: questions, answers, questions. Compend Cont Educ Pract. 1992;14:127-53.

2. Elliott J, Barber PJ. Feline chronic renal failure: clinical findings in 80 cases diagnosed between 1992 and 1995. J Small Anim Pract. 1998;39(2):78-85.

3. Lund EM, Armstrong PJ, Kirk CA, Kolar LM, Klausnor JS. Health status and population characteristics of dogs and cats examined at private veterinary practices in the United States. J Am Vet Med Assoc. 1999;214:1336-41.

4. Marino CL, Lascelles BDX, Vaden SL, Gruen ME, Marks SL. Prevalence and classification of chronic kidney disease in cats randomly selected from four age groups and in cats recruited for degenerative joint disease studies. J Feline Med Surg. 2014;16(6):465-72.

5. Brown CA, Elliott J, Schmiedt CW, Brown SA. Chronic kidney disease in aged cats: clinical features, morphology, and proposed pathogeneses. Vet Pathol. 2016;53(2):309-26.

6. Lawson J, Elliott J, Wheeler-Jones C, Syme H, Jepson R. Renal fibrosis in feline chronic kidney disease: known mediators and mechanisms of injury. Vet J. 2015;203:18-26.
7. Lee SY, Kim SI, Choi ME. Therapeutic targets for treating fibrotic kidney diseases. Transl Res. 2015;165:512-30.

8. El Ghoul B, Squalli T, Servais A, Elie C, Meas-Yedid V, Trivint C, Vanmassenhove J, Grünfeld JP, Olivo-Marin JC, Thervet E, Noël LH, Prié D, Fakhouri F. Urinary procollagen III aminoterminal propeptide (PIIINP): a fibrotest for the nephrologist. Clin J Am Soc Nephrol. 2010;5:205-10.

9. Vaden SL, Levine JF, Lees GE, Groman RP, Grauer GF, Forrester SD. Renal biopsy: a retrospective study of methods and complications in 283 dogs and 65 cats. J Vet Intern Med. 2005;19(6):794-801.

10. DiBartola SP, Rutgers HC, Zack PM, Tarr MJ. Clinicopathologic findings associated with chronic renal disease in cats: 74 cases (1973-1984). J Am Vet Med Assoc. 1987;190(9):1196-202.

11. King JN, Tasker S, Gunn-Moore DA, Strehlau G. Prognostic factors in cats with chronic kidney disease. J Vet Intern Med. 2007;21(5):906-16.

12. Paepe $D$, Daminet $S$. Feline CKD: Diagnosis, staging and screening-what is recommended? J Feline Med Surg. 2013;15(1_suppl):15-27.

13. Grooters AM, Biller DS. Ultrasonographic findings in renal disease. In: Bonagura JD, Kirk RW, editors. Current veterinary therapy XII small animal practice. Philadelphia: Saunders; 1995. p. 993-36.

14. Widmer WR, Biller DS, Adams LG. Ultrasonography of the urinary tract in small animals. J Am Vet Med Assoc. 2004;225(1):46-54

15. Debruyn K, Haers H, Combes A, Paepe D, Peremans K, Vanderperren K, Saunders $\mathrm{JH}$. Ultrasonography of the feline kidney: technique, anatomy and changes associated with disease. J Feline Med Surg. 2012;14(11):794-803.

16. Penninck D, d'Anjou MA. Gastrointestinal tract. In: Atlas of small animal ultrasonography. 2nd ed. Chichester: Wiley; 2015. p. 265-306.

17. Paepe D, Bavegems V, Combes A, Saunders JH, Daminet S. Prospective evaluation of healthy ragdoll cats for chronic kidney disease by routine laboratory parameters and ultrasonography. J Feline Med Surg. 2013; 15(10):849-57.

18. Soylemezoglu O, Wild G, Dalley AJ, MacNeil S, Milford-Ward A, Brown CB, El Nahas AM. Urinary and serum type III collagen: markers of renal fibrosis. Nephrol Dial Transplant. 1997;12:1883-9.

19. Teppo AM, Törnroth T, Honkanen E, Grönhagen-Riska C. Urinary aminoterminal propeptide of type III procollagen (PIIINP) as a marker of interstitial fibrosis in renal transplant recipients. Transplantation. 2003;75:2113-9.

20. Ix JH, Biggs ML, Mukamal K, Djousse L, Siscovick D, Tracy R, Katz R, Delaney JA, Chaves P, Rifkin DE, Hughes-Austin JM, Garimella PS, Sarnak MJ, Shlipak $M G$, Kizer JR. Urine collagen fragments and CKD progression-the cardiovascular health study. J Am Soc Nephrol. 2015;26:2494-503.

21. Glińska-Suchocka K, Orłowska A, Jankowski M, Kubiak K, Spużak J. Serum concentrations of PIIINP aminopeptide in dogs with liver fibrosis. Pol J Vet Sci. 2016;19(2):365-9.

22. Heikkilä HP, Krafft E, Jespers P, McEntee K, Rajamäki MM, Clercx C. Procollagen type III amino terminal propeptide concentrations in dogs with idiopathic pulmonary fibrosis compared with chronic bronchitis and eosinophilic bronchopneumopathy. Vet J. 2013;196(1):52-6.

23. Hezzell MJ, Boswood A, Chang YM, Moonarmart W, Elliott J. Associations among serum $\mathrm{N}$-terminal procollagen type III concentration, urinary aldosterone-to-creatinine ratio, and ventricular remodeling in dogs with myxomatous mitral valve disease. Am J Vet Res. 2012;73(11):1765-74.

24. Lin HY, Lee YL, Lin KD, Chiu YW, Shin SJ, Hwang SJ, Chen HC, Hung CC. Association of renal elasticity and renal function progression in patients with chronic kidney disease evaluated by real-time ultrasound elastography. Sci Rep. 2017;7:43303.

25. Peng L, Zhong T, Fan Q, Liu Y, Wang X, Wang L. Correlation analysis of renal ultrasound elastography and clinical and pathological changes in patients with chronic kidney disease. Clin Nephrol. 2017;87(6):293-300.

26. Sigrist RMS, Liau J, El Kaffas A, Chammas MC, Willmann JK. Ultrasound elastography: review of techniques and clinical applications. Theranostics. 2017;7(5):1303.

27. Grenier N, Gennisson JL, Cornelis F, Le Bras Y, Couzi L. Renal ultrasound elastography. Diagn Interv Imaging. 2013;94(5):545-50.

28. Guo LH, Xu HX, Fu HJ, Peng A, Zhang YF, Liu LN. Acoustic radiation force impulse imaging for noninvasive evaluation of renal parenchyma elasticity: preliminary findings. PLoS One. 2013;8(7):e68925.

29. Holdsworth A, Bradley K, Birch S, Browne WJ, Barberet V. Elastography of the normal canine liver, spleen and kidneys. Vet Radiol Ultrasound. 2014; 55(6):620-7.

30. Goddi A, Bonardi M, Alessi S. Breast elastography: a literature review. Ultrasound. 2012;15:192-8. 
31. Hassan K, Loberant N, Abbas N, Fadi H, Shadia H, Khazim K. Shear wave elastography imaging for assessing the chronic pathologic changes in advanced diabetic kidney disease. Ther Clin Risk Manag. 2016;12:1615-22.

32. Hu Q, Gou Y, Sun C, Ding W, Xu K, Gu B, Xia G, Ding Q. The prognostic value of $C$-reactive protein in renal cell carcinoma: a systematic review and meta-analysis. Urol Oncol. 2014;32:50.e1-8.

33. Samir AE, Dhyani M, Anvari A, Prescott J, Halpern EF, Faquin WC, Stephen A. Shear-wave elastography for the preoperative risk stratification of follicularpatterned lesions of the thyroid: diagnostic accuracy and optimal measurement plane. Radiology. 2015;277(2):565-73.

34. White J, Gay J, Farnsworth R, Mickas M, Kim K, Mattoon J. Ultrasound elastography of the liver, spleen, and kidneys in clinically normal cats. Vet Radiol Ultrasound. 2014;55(4):428-34.

35. International Renal Interest Society (IRIS). Elanco animal health. CKD staging in cats (2013). Disponível em: http://www.iris-kidney.com/pdf/IRIS_2017_ Staging_of_CKD_09May18.pdf. Accessed Jan 2019.

36. Buranakarl C, Ankanaporn K, Thammacharoen S, Trisirisoj M. Relationships between degree of azotaemia and blood pressure, urinary protein: creatinine ratio and fractional excretion of electrolytes in dogs with renal azotaemia. Vet Res Commun. 2007;31:245-57.

37. Donald RA, Pradeep PP. The science and engineering of materials. 2nd ed. Stamford: Thomson learning Press; 2004. p. 234-57.

38. Franchi-Abella S, Elie C, Correas JM. Ultrasound elastography: advantages, limitations and artefacts of the different techniques from a study on a phantom. Diagn Interv Imaging. 2013;94:497-501.

39. Berchtold L, Friedli I, Vallée JP, Moll S, Martin PY, Seigneux SD. Diagnosis and assessment of renal fibrosis: the state of the art. Swiss Med Wkly. 2017; 147:w14442

40. Jeon S, Lee G, Lee SK, Kim H, Yu D, Choi J. Ultrasonographic elastography of the liver, spleen, kidneys, and prostate in clinically normal beagle dogs. Vet Radiol Ultrasound. 2015;56:425-31.

41. Feliciano MAR, Ramirez RAU, Maronezi MC, Maciel GS, Avante ML, Senhorello ILS, Mucédola T, Gasser B, Carvalho CF, Vicente WRR. Accuracy of four ultrasonography techniques in predicting histopathological classification of canine mammary carcinomas. Vet Radiol Ultrasound. 2018:1-9.

42. Feliciano MAR, Uscategui RAR, Maronezi MC, Simões APR, Silva P, Gasser B, Pavan L, Carvalho CF, Canola JC, Vicente WRR. Ultrasonography methods for predicting malignancy in canine mammary tumors. PLoS One. 2017;12: e0178143.

43. Seiler GS, Griffith E. Comparisons between elastographic stiffness scores for benign versus malignant lymph nodes in dogs and cats. Vet Radiol Ultrasound. 2018;59:79-88.

44. Bamber J, Cosgrove D, Dietrich CF, Fromageau J, Bojunga J, Calliada F, Cantisani V, Correas JM, D'Onofrio M, Drakonaki EE, Fink M, Friedrich-Rust M, Gilja OH, Havre RF, Jenssen C, Klauser AS, Ohlinger R, Saftoiu A, Schaefer F, Sporea I, Piscaglia F. EFSUMB guidelines and recommendations on the clinical use of ultrasound elastography. Part 1: basic principles and technology. UiM/EJU. 2013;34:169-84.

45. Gennisson JL, Deffieux T, Fink M, Tanter M. Ultrasound elastography: principles and techniques. Diagn Interv Imaging. 2013;94:487-95.

46. Stock E, Paepe D, Daminet S, Vandermeulen E, Duchateau L, Saunders JH, Vanderperren K. Contrast-enhanced ultrasound examination for the assessment of renal perfusion in cats with chronic kidney disease. J Vet Intern Med. 2018;32:260-6.

47. Matos I, Azevedo P, Carreira LM. Pilot study to evaluate the potential use of the renal resistive index as a preliminary diagnostic tool for chronic kidney disease in cats. J Feline Med Surg. 2017;20(10):940-7.

48. Shiroma JT, Gabriel JK, Carter RL, Scruggs SL, Stubbs PW. Effect of reproductive status on feline renal size. Vet Radiol Ultrasound. 1999:40:242-5.

49. Seiler GS. The kidneys and ureters. In: Thrall DE, editor. Textbook of veterinary diagnostic radiology. 6th ed. St Louis: Elsevier Saunders; 2013. p. 812-24.

50. Singh H, Panta OB, Khanal U, Ghimire RK. Renal cortical Elastography: Normal values and variations. J Med Ultrasound. 2017;25:215-20.

51. Prunotto M, Ghiggeri G, Bruschi M, Gabbiani G, Lescuyer P, Hocher B, Chaykovska L, Berrera M, Moll S. Renal fibrosis and proteomics: current knowledge and still key open questions for proteomic investigation. J Proteome. 2011;74(10):1855-70.

52. Risdon RA, Sloper JC, De Wardener HE. Relationship between renal function and histological changes found in renal-biopsy specimens from patients with persistent glomerular nephritis. Lancet. 1968;292(7564):363-6.
53. Nath KA. Tubulointerstitial changes as a major determinant in the progression of renal damage. Am J Kidney Dis. 1992;20(1):1-17.

54. Yabuki A, Mitani S, Fujiki M, Misumi K, Endo Y, Miyoshi N, Yamoto O. Comparative study of chronic kidney disease in dogs and cats: induction of myofibroblasts. Res Vet Sci. 2010;88(2):294-9.

55. Chakrabarti S, Syme HM, Brown CA, Elliott J. Histomorphometry of feline chronic kidney disease and correlation with markers of renal dysfunction. Vet Patholy. 2013;50(1):147-55.

56. Futrakul $P$, Yenrudi S, Futrakul N, Sensirivatana R, Kingwatanakul $P$, Jungthirapanich J, Cherdkiadtikul T, Laohapaibul A, Watana D, Singkhwa V, Futrakul S, Pongsin P. Tubular function and tubulointerstitial disease. Am J Kidney Dis. 1999;33(5):886-91.

57. Clarkson CE, Fletcher TF. Anatomy of the kidney and proximal ureter. In: Bartges J, Polzin DJ, editors. Nephrology and urology of small animals. Chichester: Wiley; 2011. p. 1-9.

58. DiBartola SP. Applied renal physiology. In: Di Bartola SP, editor. Fluid, Electrolyte, and Acid-Base Disorders in Small Animal Practice. 4th ed. St Louis: Elsevier; 2012. p. 26-43.

59. DiBartola SP. Applied renal physiology. In: Di Bartola SP, editor. Fluid, Electrolyte, and Acid-Base Disorders in Small Animal Practice. 4th ed. St Louis: Elsevier; 2012. p. 2-23.

60. Lawson JS, Syme HM, Wheeler-Jones CPD, Elliott J. Urinary active transforming growth factor $\beta$ in feline chronic kidney disease. Vet J. 2016; 214:1-6.

61. Mansour SG, Puthumana J, Coca SG, Gentry M, Parikh CR. Biomarkers for the detection of renal fibrosis and prediction of renal outcomes: a systematic review. BMC Nephrol. 2017;18:72.

62. Habenicht LM, Webb TL, Clauss LA, Dow SW, Quimby JM. Urinary cytokine levels in apparently healthy cats and cats with chronic kidney disease. J Feline Med Surg. 2013;15(2):99-104.

63. Lawson J, Elliott J, Wheeler-Jones C, Syme H, Jepson R. Renal fibrosis in feline chronic kidney disease: known mediators and mechanisms of injury. Vet J. 2015:203(1):18-26.

\section{Ready to submit your research? Choose BMC and benefit from:}

- fast, convenient online submission

- thorough peer review by experienced researchers in your field

- rapid publication on acceptance

- support for research data, including large and complex data types

- gold Open Access which fosters wider collaboration and increased citations

- maximum visibility for your research: over $100 \mathrm{M}$ website views per year

At BMC, research is always in progress.

Learn more biomedcentral.com/submissions 